\title{
REAL TIME NEUTRON RADIOGRAPHY USING A LIXI NEUTRON IMAGING DEVICE
}

\author{
John T. I.INDSAY and John D. JONES \\ Phoenix Memorial Laboratory, The University of Michigan, Ann Arbor, Michigan 48109, USA \\ Charles W. KAUFFMAN \\ Aerospace Engineering, The University of Michigan, Ann Arbor, Michigan 48109, USA
}

Bruce VAN PELT

Lixi Inc., Downers Grove, Illinois 60515, USA

\begin{abstract}
A real time neutron radiography system has been developed at the University of Michigan Phoenix Memorial Laboratory (PML) and has recently been used to test the imaging capabilities of a neutron imaging device developed by Lixi, Inc. of Downers Grove, Ill. This device uses an input phosphor that is high in gadolinium to generate a light image which is then sent through an intensifier stage to provide images that can be viewed by eye, video camera, or standard $35 \mathrm{~mm}$ camera. It was determined that this device provides images of much higher resolution and sensitivity than those obtained with the imaging system currently being used at PML. Using computerized image enhancement techniques, the images obtained with the Lixi neutron imaging device can then be futher enhanced or processed to obtain quantitative information on the object being imaged.
\end{abstract}

\section{Introduction}

The real time neutron radiography facility at the University of Michigan Phoenix Memorial Laboratory (PML) was developed to provide a research tool which makes use of the unique properties of neutrons to study phenomena which cannot be studied using existing methods. Neutrons interact with atomic nuclei rather than orbitral electrons as is the case with X-rays. This provides a method of radiography that complements $X$-ray radiography and often results in the ability to image phenomena that $X$-ray radiography is incapable of $[1,6]$. One of the most significant advantages of neutron radiography is the ability to image hydrogenous substances inside metallic materials such as lubricants, coolants, and fuels inside aluminum engines [4]. By using real time neutron radiography, one can then study dynamic events such as the movement of liquids inside solids [5]. This has led to the dynamic study of fuels, lubricants, and coolants in operating systems at PML [2].

\section{Facility}

The real time neutron radiography facility at PML is located at the Ford Nuclear Reactor on the North Campus of the University of Michigan. This facility, fig. 1 , uses a $2 \mathrm{MW}$ thermal pool type reactor to produce the neutrons which are collimated and then passed through the object to be radiographed to the imaging system. Currently, the imaging system at PML, fig. 2, consists of (1) a gadolinium oxysulfide screen mounted in a light tight box, (2) a front surface mirror to reflect the image at right angle to the screen, (3) a $f=0.8$ lens, and (4) an EMI magnetically focused image intensifier tube. The EMI tube may be viewed by a variety of lenses and video cameras depending on the requirements of the experiment. The video signal is then sent to a Quantex QX-9200 image processing system. This is an IBM 9002 laboratory computer based real time image processing system which has a library of several preprogrammed image processing routines and can also use custom routines written by the user.

\section{The Lixi neutron imaging device}

A Lixi neutron imaging device manufactured by Lixi, Inc. of Downers Grove, Ill, was obtained for comparitive testing. This device uses a high resolution gadolinium oxysulfide input screen coupled by fiber optics to an image intensifier tube to produce an output image which can be viewed by a video camera or a 35 $\mathrm{mm}$ camera. It was originally designed for low intensity $\mathrm{X}$ - or gamma imaging [3]. However, because of its gadolinium oxysulfide screen, it was assumed that it could also be used as an excellent neutron imaging 


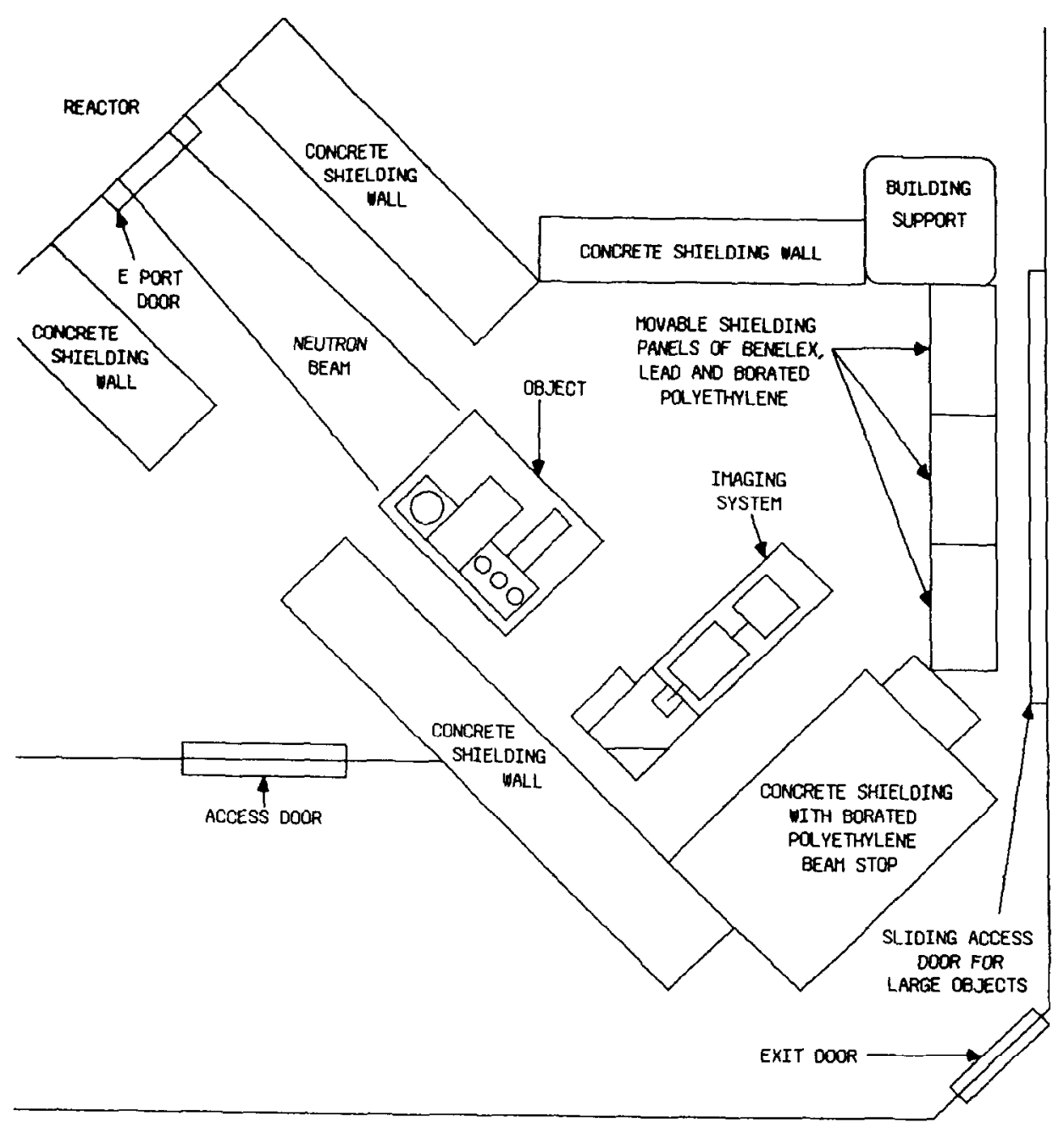

Fig. 1. Real time neutron radiography facility at the University of Michigan Phoenix Memorial Laboratory (PML).

device. The input image size is 2 in. with an output viewing screen of approximately 2 in. The same video/Quantex image processing system was used with the Lixi device. The neutron imaging device was tested for sensitivity, contrast, and resolution and then compared with the EMI imaging system.

\section{Test devices}

Fig. 3 shows several penetrameters used to determine the imaging capability of the Lixi neutron imaging device. These penetrameters were constructed of 6061 aluminum and then filled with the liquid to be studied. The various types of penetrameters used were: (1) hole penetrameters, tubular columns of various diameters, (2) step wedges of various thicknesses to study film thickness sensitivity, contrast, and film edge determina- tion, (3) continuous wedges, continuously varying wedges used to study film edge thickness and latitude, and (4) double penetrameters used to compare different liquids at the same time.

\section{Results}

Fig. 4 shows an image obtained on the EMI imaging system using oil in a holc penetramcter whose smallest diameter is $0.052 \mathrm{in}$. The $0.052 \mathrm{in}$. tubular diameter is just discernible. Fig. 5 shows a similar penetrameter using the Lixi device. The smallest tubular diameter in fig. 5 is $0.040 \mathrm{in}$. This is easily visable and a considerable improvement over the image of fig. 4 obtaincd with the EMI system. Fig. 6 shows an image of a step wedge with thicknesses of $0.020,0.040$ and $0.060 \mathrm{in}$. using water as the liquid. This shows clear contrast at this 


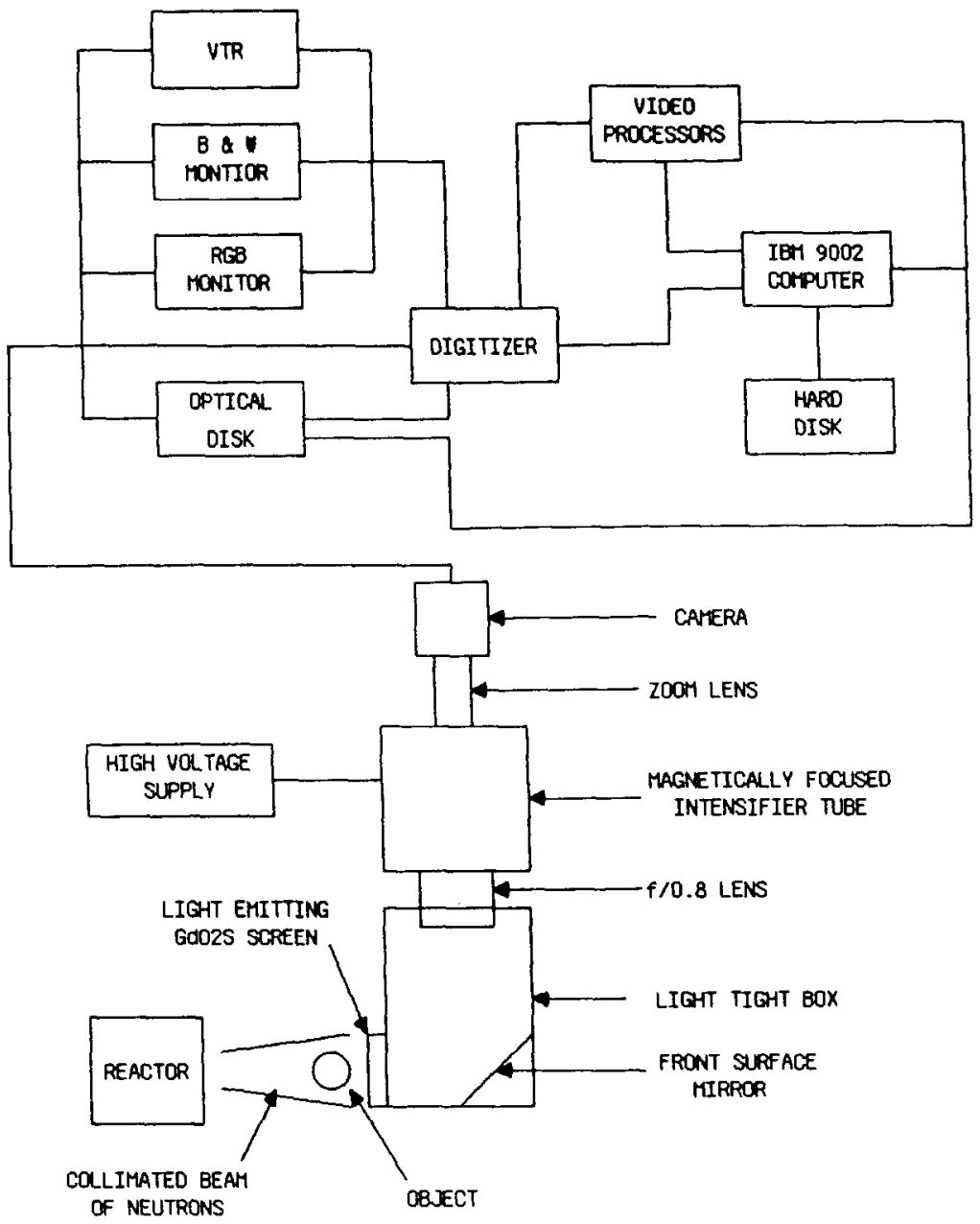

Fig. 2. Schematic of the PML real time neutron radiography imaging system.

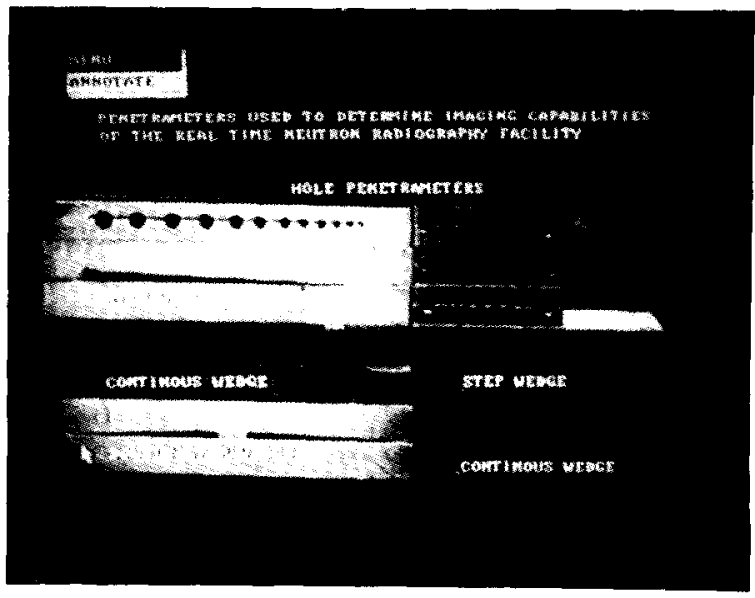

Fig. 3. Penetrameters used to determine imaging capabilities of the real time neutron radiography facility.

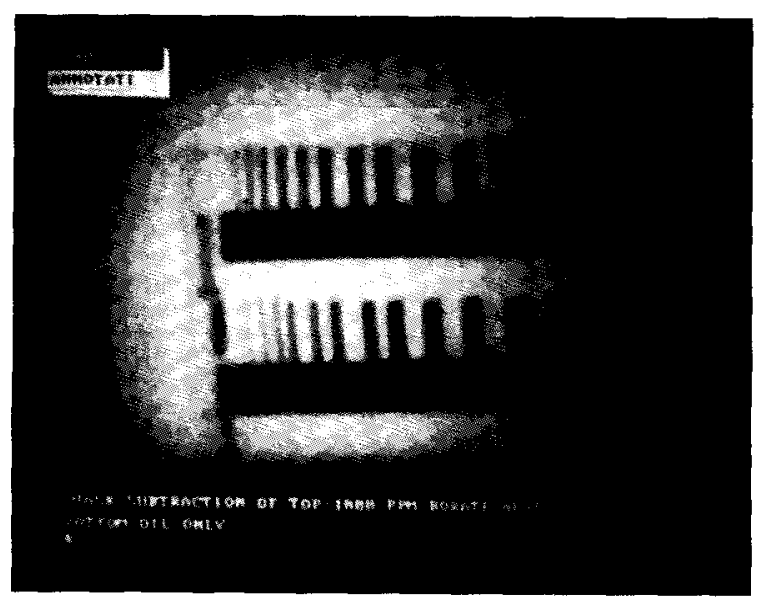

Fig. 4. Hole penetrameter with oil using the FMl imaging system, smallest diameter shown is $0.052 \mathrm{in}$. 


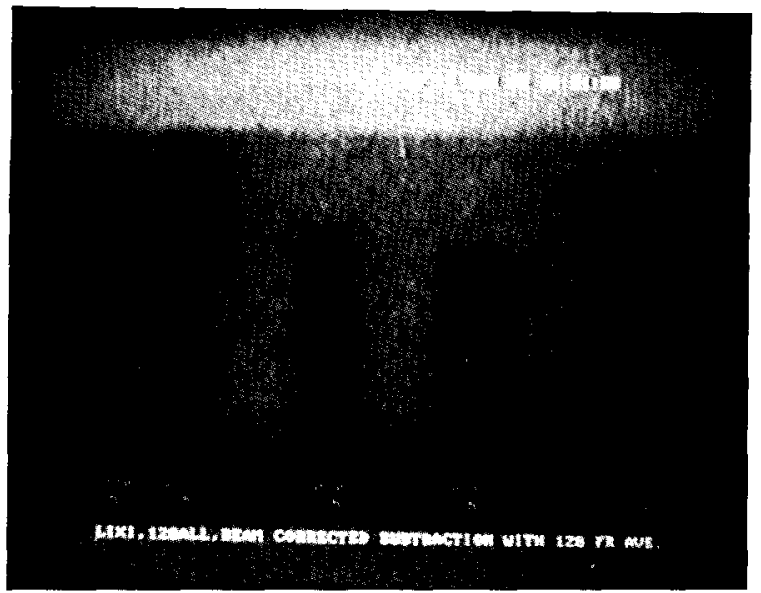

Fig. 5. Hole penetrameter with water using the Lixi neutron imaging device, smallest diameter shown is $0.040 \mathrm{in}$.

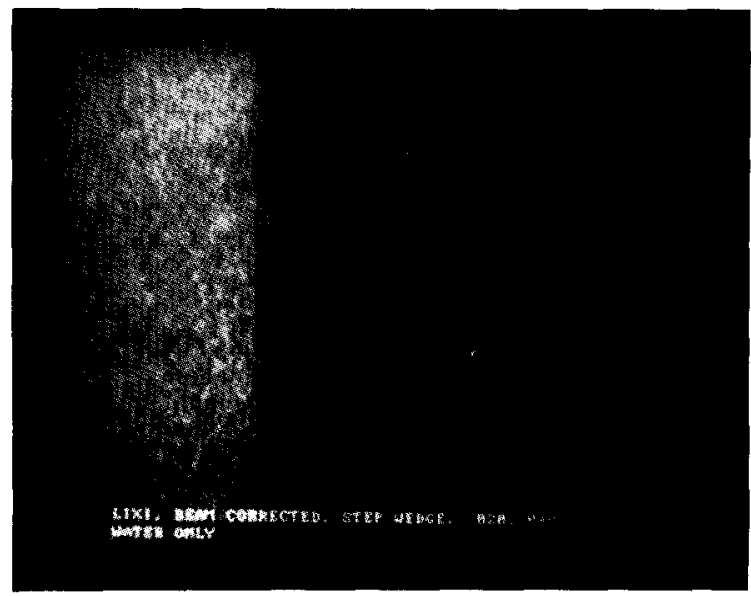

Fig. 6. Step wedge with $0.020,0.040$ and 0.060 in. thicknesses of water. Lixi.

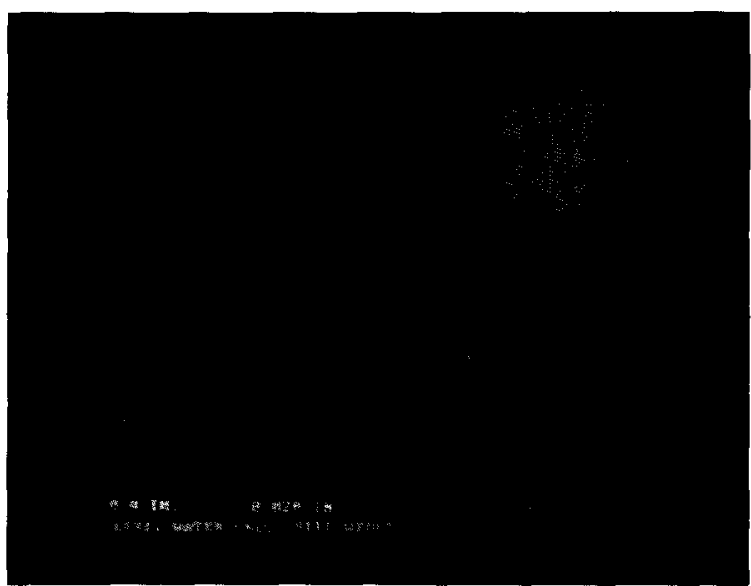

Fig. 7. Step wedge with $0.0,0.020$ and 0.040 in. thicknesses of water, Lixi, illustration of film thickness contrast as well as film edge detection.

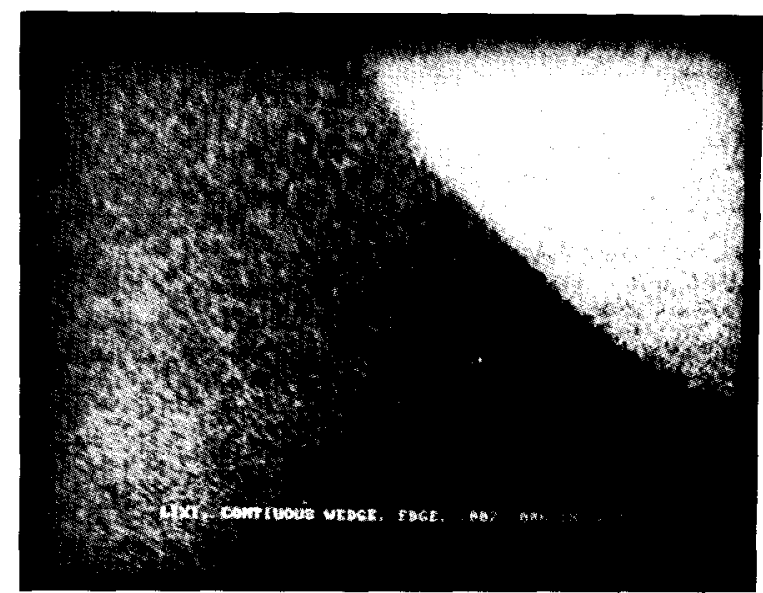

Fig. 8. Continuous wedge, film edge visable is from 0.002 to 1).006 in. thickness, Lixi.

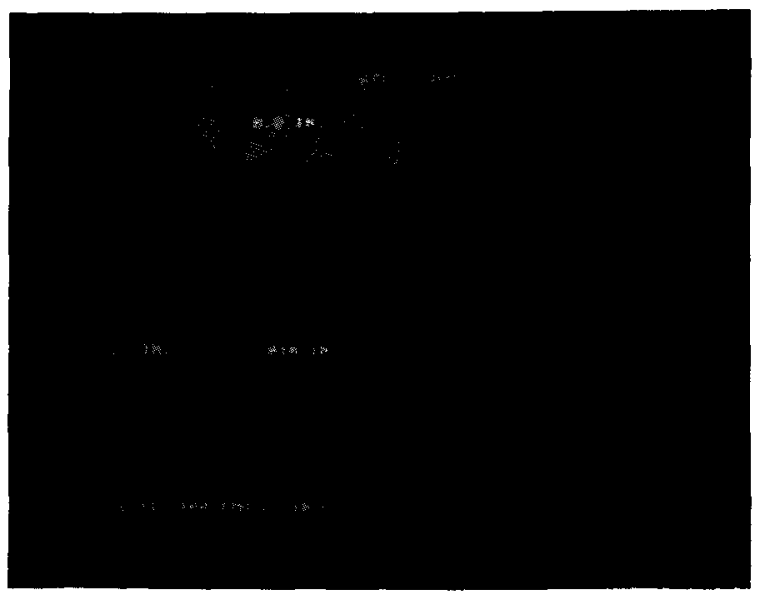

Fig. 9. Step wedge with $0.005,0.010$ and 0.015 in. thicknesses using $100 \mathrm{ppm}$ Gd in water, Lixi.

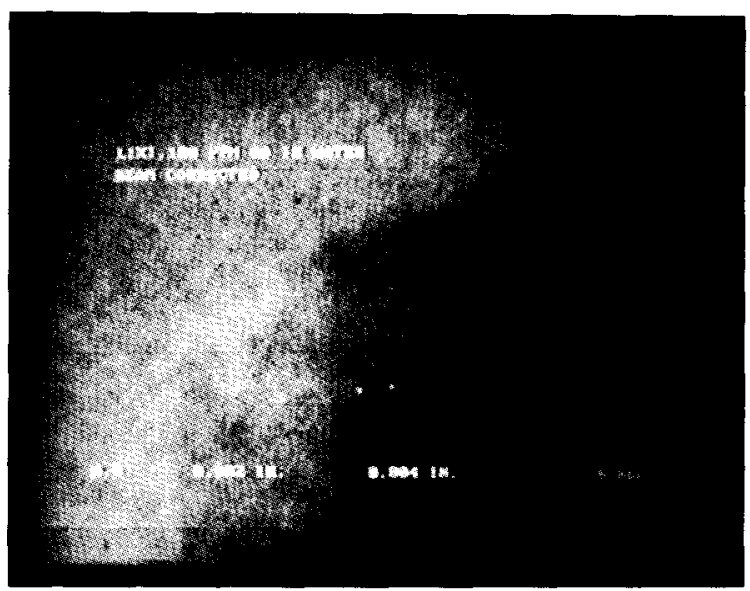

Fig. 10. Step wedge with $0.002,0.004$ and 0.006 in. thicknesses using $100 \mathrm{ppm} \mathrm{Gd}$ in water, Lixi. 


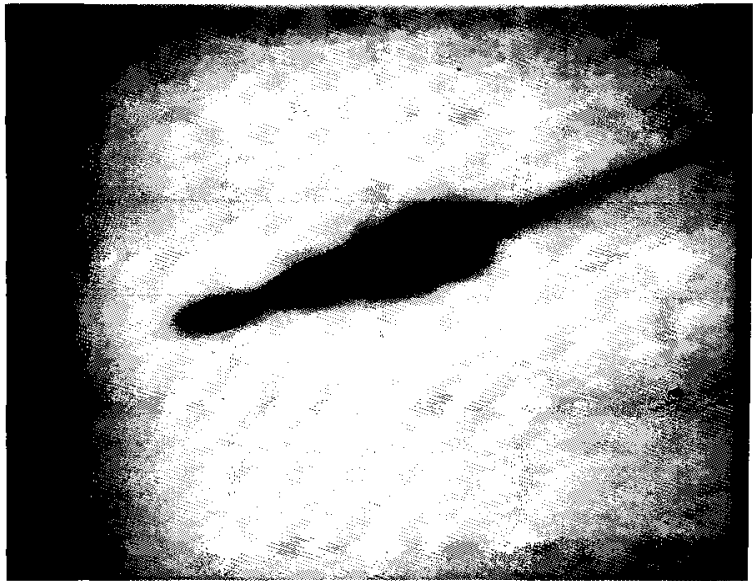

Fig. 11. Subtraction image of a spray nozzle using the EMI system

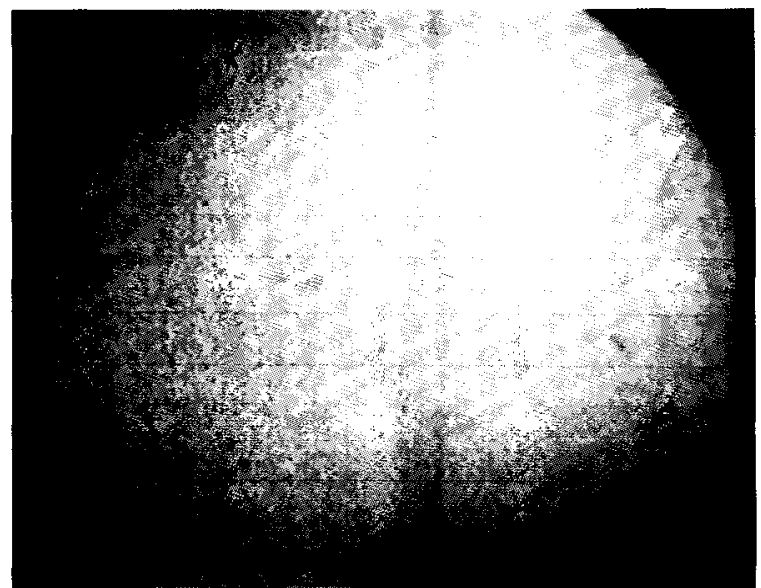

Fig. 12. Real time image of the same spray nozzle using the Lixi system.

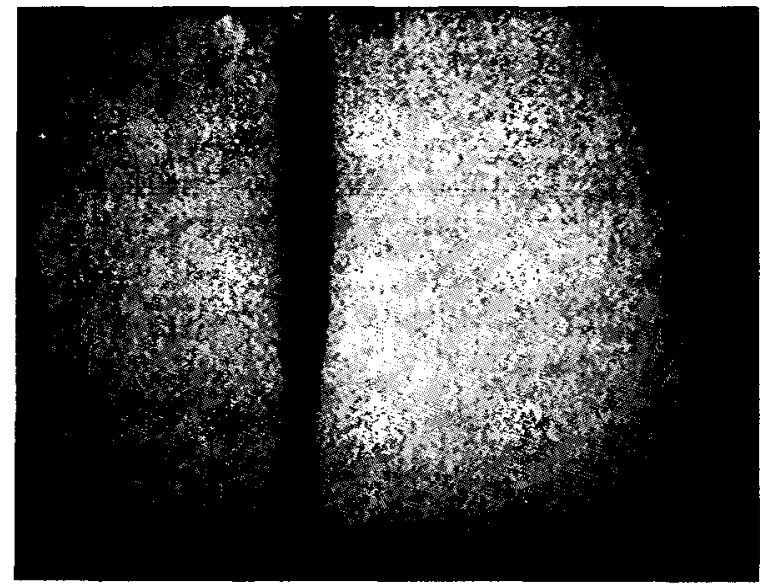

Fig. 13. Subtraction image of the same spray nozzle using the Lixi system.

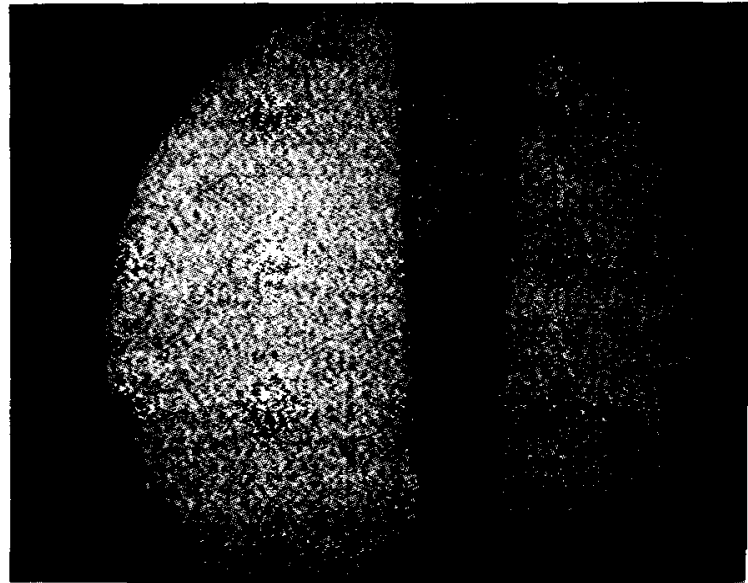

Fig. 14. Subtraction image of the same spray at a higher pressure using the Lixi system.

level of water thickness. Fig. 7 shows a different section of this penetrameter showing the contrast level between $0.0,0.020$ and $0.040 \mathrm{in}$ as well as showing clearly the edges of the liquid. Fig. 8 shows the image obtained using a continuous wedge. The film edge can be easily seen in the region from 0.002 to $0.006 \mathrm{in}$. and a general left to right thickness gradient can be seen. Fig. 9 shows another step wedge with thicknesses of 0.005. 0.010 and 0.015 in. using $100 \mathrm{ppm}$ gadolinium in water as the liquid. The different thicknesses are easily seen as well as the edge of the films. Fig. 10 shows another step wedge with thicknesses of $0.002,0.004$ and 0.006 in. This image shows the high sensitivity of the Lixi device to small thicknesses of liquid films as well as the edges of those films. An example of the Lixi device applied to a real time process was demonstrated using water sprays. Fig. 11 shows a computer subtraction image of a flat tip nozzle spray obtained using the EMI imaging system. Fig. 12 is a real time image of the same spray using the Lixi device showing greater resolution and sensitivity prior to any image processing. Fig. 13 is a subtraction image of the same spray nozzle using the LIXI device. Fig. 14 is a computer mask subtraction image of the same nozzle operating at a higher pressure. This illustrates the ability to differentiate the spray profile as a function of pressure.

\section{Summary}

In summary, the Lixi neutron imaging device showed greater sensitivity and resolution than the EMI imaging system but was limited by its lack of pulsing capability and by the relatively small 2 in. diameter input. Ihis device should however, prove to be extremely useful in the field of real time neutron radiography where high 
resolution is important or where there are space limitations dictated by the test object.

\section{References}

[1] J.T. Lindsay, PhD Disertation, University of Missouri (1983).

[2] J.D. Jones, J.T. Lindsay, C.W. Kauffman, A. Vulpeti and B. Peters, SAE Technical Paper Series No. 850560, International Congress and Exposition (1985).
[3] Lo I Yin, J.I. Trombka and S.M. Steltzer, Nucl. Instr. and Meth. 158 (1979) 175.

[4] H. Berger. Practical Applications of Neutron Radiography and Gaging, ASTM STP 586 (1976).

[5] G.S. Okawara and A.A. Harms, Nucl. Technol. 31 (1976).

[6] M. Kuriyama, W.J. Boettinger and H.F. Burdette, RealTime Radiologic Imaging: Medical and Industrial Applications, ASTM STP 716, eds., D.A. Garret and D.A. Bracher ( $\Lambda$ merican Society for Testing and Materials, 1980). 